\title{
Using air curtains to reduce short-range infection risk in consulting ward: A numerical investigation
}

\author{
Jin Ye ${ }^{1,2}$, Hua Qian ${ }^{1,2}(\bowtie)$, Jianchao Ma ${ }^{1,2}$, Rong Zhou ${ }^{3,4}$, Xiaohong Zheng ${ }^{1,2,5}$ \\ 1. School of Energy and Environment, Southeast University, Nanjing 210096, China \\ 2. Engineering Research Center of BEEE, Ministry of Education of China, Nanjing 210096, China \\ 3. First Affiliated Hospital of Guangzhou Medical University, Guangzhou 510000, China \\ 4. Guangzhou Angel Biosafety Co., Ltd, Guangzhou 510000, China \\ 5. Jiangsu Provincial Key Laboratory of Solar Energy Science and Technology, Nanjing, 210096, China
}

\begin{abstract}
Air curtains is promising in reducing the short-range infection risk in hospitals. To quantitatively evaluate its performance, this paper explores air curtains equipped on normal consulting desk to avoid doctor's direct exposure to the patient exhaled pollutants. A numerical investigation is conducted to evaluate the effects of supply air velocity and angle on cutting off performance. Simulation results show that the average mass fraction of exhaled pollutants decreases significantly (70\%-90\%) in the consulting ward, indicating satisfying performance of air curtains. Increasing supply air velocity is demonstrated to be conducive in forming full air curtains, whereas an excessively high supply air velocity may be of adverse effects by entraining exhaled flow. Besides, the supply air angle is also critical due to its coupling with supply air velocity. It is found that larger angle $\left(0^{\circ}-40^{\circ}\right)$ is better where velocity is less than $3 \mathrm{~m} / \mathrm{s}$, otherwise a small angle $\left(20^{\circ}\right)$ is preferable where velocity is larger than $3 \mathrm{~m} / \mathrm{s}$. Exhaled flow could be well suppressed the supply air angle $20^{\circ}$ but moves over air curtains at $40^{\circ}$. This study can provide effective and intuitive guidance in applying air curtains in consulting wards.
\end{abstract}

\author{
Keywords \\ air curtains, \\ consulting ward, \\ cutting off performance, \\ numerical investigation \\ Article History \\ Received: 22 December 2019 \\ Revised: 07 April 2020 \\ Accepted: 09 April 2020 \\ (c) Tsinghua University Press and \\ Springer-Verlag GmbH Germany, \\ part of Springer Nature 2020
}

\section{Introduction}

Hundreds of millions of people suffer and four million people die prematurely from respiratory diseases each year (Ferkol and Schoraufnagel 2014). The emerging outbreak of 2019 novel coronavirus diseases (COVID-19) has caused globally 78,811 infection cases in 29 countries, 77,042 of which occurred in China by Feb 23, 2020 (WHO 2020). Pointing to the risk to medical staff, the Chinese Center for Disease Control and Prevention (CCDC) suggested that a total of 3019 health workers have been infected (1,716 confirmed cases) and five deaths of health workers have been reported (Novel Coronavirus Pneumonia Emergency Response Epidemiology Team 2020). This ongoing respiratory infectious disease COVID-19 again alarmed and focused on precaution and protection of health staff in hospital environments.

Respiratory infectious diseases can be transmitted by direct/indirect contact, fomite (such as droplets from E-mail: qianh@seu.edu.cn respiratory tract) and airborne over large distance (Eames et al. 2009). Liu et al. (2017b) proposed the short-range transmission mode, which includes both the conventional large droplet route and the newly-defined short-range airborne transmission with a threshold distance of $1.5 \mathrm{~m}$. Much higher infection risk is observed within the short-range distance (Lidwell and Williams 1961; Xie et al. 2007; Liu et al. 2017b). Further studies showed that the threshold range of short-range airborne may be related to relative humidity and temperature gradient in the room (Lidwell and Williams 1961; Nielsen et al. 2008; Gil-Lopez et al. 2014). Face to face between an infector and a doctor in short range distance is very common in hospital consulting wards. In these wards, there is generally a consulting desk located, by which a doctor and a patient sit oppositely. The distance between the doctor and the patient is normally $1.0 \mathrm{~m}-1.5 \mathrm{~m}$, resulting in the doctor being directly exposed to the exhaled flow of the patient. 
Abundant studies have explored airborne transmission of respiratory infections in hospitals and its prevention since the SARS outbreak in 2003 (Li et al. 2005; Zhou et al. 2017; Saarinen et al. 2018; Liu et al. 2019). Increasing the distance from the infection source is a practically easy way to avoid high infection risk within the short-range distance (Xie et al. 2007; Nielsen et al. 2008; Liu et al. 2017b). But it may not be feasible in consulting wards because the doctor need to communicate in close proximity with the patient to collect medical information. Medical (or surgical) masks and respirators are widely used for protection of the patient as well as the health care workers (Maclntyre et al. 2013, 2015, 2016). Previous studies suggest that masks worn by the infection source works more efficiently than worn by susceptible person (Inouye et al. 2006; Tang et al. 2009). Tang et al. revealed that both surgical and N95 masks thwart human coughing from projecting a rapid turbulent jet into the surrounding air (Tang et al. 2009). But in many cases, patients are not aware of the significance of wearing masks, resulting in seeing doctor without wearing a mask. The facts encourage us to consider an engineering method to reduce short-range airborne infections.

The air curtains, generated from certain equipment, are widely used for pollutant control, thermal and moisture control, such as thermal and moisture control to save energy (Goubran et al. 2017), the sealing entrance of cold storage rooms (Gil-Lopez et al. 2014), the openings of refrigerated food display cabinets (Cao et al. 2011; Laguerre et al. 2012), smoke confinement (Shih et al. 2011). The Protected Occupied Zone Ventilation (POV) and Protected Zone Ventilation (PZV) technique apply air curtains and display good performance in cutting off the airborne transmission route (Cao et al. 2015). The protection efficiency is found to vary from $8 \%$ to $50 \%$ depending on the supply air velocity, exhaust location and the usage of partitions (Cao et al. 2014). Cao et al. (2015) found that the dimensionless concentration with the supply air velocity increased to $4 \mathrm{~m} / \mathrm{s}$ in the downward plane jet is $40 \%$ lower than for fully mixed ventilation. These studies also found that the cutting off performance of air curtains in controlling pollutants is determined by multiple variables, including supply velocity, ejection angle, and room geometries (Amin et al. 2011; Shih et al. 2011). Shih et al. (2011) presented an application of using an air curtain to resolve the personnel safety concern for emergency management in a contaminated cleanroom and found an optimal sealing outcome of air curtains realized at ejection velocity $5 \mathrm{~m} / \mathrm{s}$ (varying $3 \mathrm{~m} / \mathrm{s}, 5 \mathrm{~m} / \mathrm{s}, 7 \mathrm{~m} / \mathrm{s}$ ) and ejection angle $15^{\circ}$ (varying $0^{\circ}, 15^{\circ}, 30^{\circ}$ ). Zhao et al. (2018) numerically investigated the airborne pollutant separation by the air curtain installed on the ceiling level and revealed that the sealing efficiency increases positively with ejection velocity. However, the performance of air curtains in mitigating the short-range transmission in hospital consulting wards has not been studied yet.

In respect to the specialty in consulting wards, this paper proposed the new application of air curtains equipped on consulting desk to reduce the doctor's direct exposure to the patients' exhaled pollutants. A numerical investigation was carried out to explore the cutting off performance of air curtains. Different key supply air parameters, i.e. supply air velocity and supply air angle were studied. The airflow pattern and the dispersion characteristics of patient's exhaled droplets were discussed.

\section{Methods}

\subsection{Physical model}

The dimension of consulting ward is $5 \mathrm{~m}(L) \times 4 \mathrm{~m}(W) \times$ $3 \mathrm{~m}(H)$, which is common in most hospitals. The consulting desk is placed in the central of the ward with the doctor and patient models respectively sitting at each long side, shown in Figure 1. To study the exposure of the susceptible doctor, thermal breathing manikins (Topp et al. 2002) are employed to simulate the infectious patient. The air curtains are installed on the consulting desk with the dimension of $1.4 \mathrm{~m}(L) \times 0.75 \mathrm{~m}(W) \times 0.75 \mathrm{~m}(H)$. The return air is discharged from two return air vents with the size of $0.28 \mathrm{~m}$ $(L) \times 0.10 \mathrm{~m}(W)$ located at both sides of the consulting desk. HEPA (High Efficiency Particulate Air) is installed inside the consulting desk to ensure clean supply air. The air curtains contribute as inlets, providing supply air after being purified by HEPA. The two outlets were located on both sides of the consulting desk to collect return air and then purify it with HEPA. To provide stable and moderate airflow, slots with size of $0.05 \mathrm{~m}(L) \times 0.0055 \mathrm{~m}(W)$ were employed in air curtains. As shown in Figure 1, the slots were double distributed along with air curtains, which were $0.45 \mathrm{~m}$ away from the edge of the desk. Totally 72 slots were

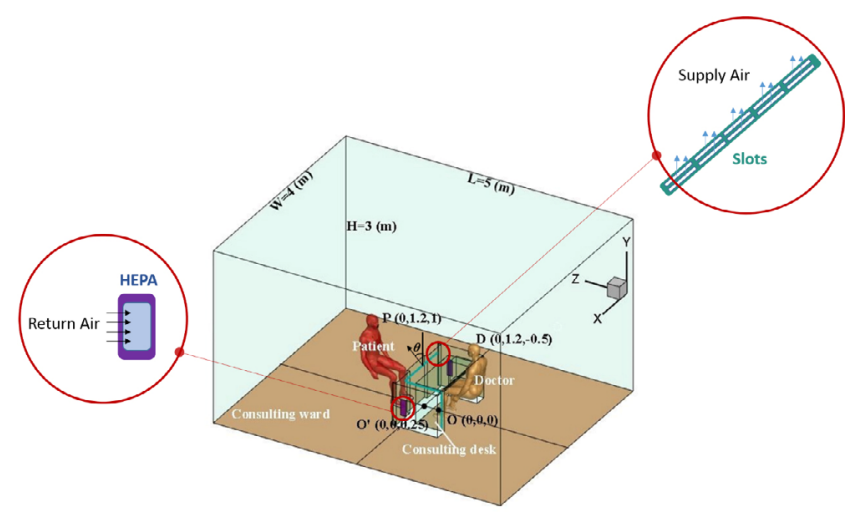

Fig. 1 The layout of consulting ward with a consulting desk between the doctor (D) and the patient (P) 
located, i.e. $40,16,16$ on length $(L)$, width $(W)$, and height $(H)$ directions, respectively.

\subsection{Model assumptions}

(1) Only exhalation from the patient' mouth and inhalation of doctor's mouth is considered to explore the exposure of the doctor to the patient exhaled pollutants.

(2) Liquid droplets begin to evaporate until the inner nuclei are left as soon as they leave the patient's mouth. During the evaporation process, droplets remain spherical hypothetically (Ji et al. 2018).

(3) Only gravity, buoyancy and drag force are considered, while other forces are able to be neglected according to literature (Xie et al. 2007; Ji et al. 2018). The droplet density is set to be $998.2 \mathrm{~kg} / \mathrm{m}^{3}$ and its specific heat capacity is $4182 \mathrm{~kJ} /(\mathrm{kg} \mathrm{K})$.

\subsection{Simulation models}

The Realizable $k-\varepsilon$ model (Zhai et al. 2007) and the SIMPLE algorithm (Versteeg and Malalasekera 2007) are employed in this study. Heat and mass transfer between indoor air and liquid droplets are considered. Species Transport Model and Discrete Phase Model are applied to calculate the evaporation and dispersion process of patient's exhaled flow (Ji et al. 2018). $\mathrm{CO}_{2}$ was selected as tracer gas to simulate the patient exhaled pollutants with the background concentration of $\mathrm{CO}_{2}$ in the simulation model was 0 . The initial mole mass fraction of $\mathrm{CO}_{2}$ is set to be $4 \%$, which is close to the natural fraction of $\mathrm{CO}_{2}$ in exhaled flow (Wei and Li 2015).

\subsection{Boundary conditions}

There are no other heat sources in the ward with adiabatic walls, except for the doctor and patient model. The patient's mouth has a hydraulic diameter of $0.012 \mathrm{~m}$, a stable exhalation temperature of $306 \mathrm{~K}$, an initial breathing velocity of $1 \mathrm{~m} / \mathrm{s}$ and a heat source intensity of $40 \mathrm{~W} / \mathrm{m}^{2}$, without considering the radiation or latent heat (Liu et al. 2017a). The temperature of supply air is $290 \mathrm{~K}$ with different supply air velocity $(0,2$, $3,4 \mathrm{~m} / \mathrm{s})$ and supply air angle $\left(0^{\circ}, 20^{\circ}, 40^{\circ}\right)$. Detailed boundary conditions of the 10 cases are listed in Table 1 . In order to compare the cut-off performance of air curtain, we set Case 0 without air curtain as reference case. In terms of the dilution effects of airflow generated by air curtains, two air outlets on the left bottom side of the consulting desk are transferred into one air inlet and one air outlet to make

Table 1 Simulation conditions of 10 cases

\begin{tabular}{|c|c|c|c|c|}
\hline Scenario & Case & Exhaled flow of the patient & Supply air angle $\theta$ & Supply air velocity $w(\mathrm{~m} / \mathrm{s})$ \\
\hline $\begin{array}{l}0 \text { (control } \\
\text { group) }\end{array}$ & Case 0 & \multirow{19}{*}{$\begin{array}{l}\text { Exhaled velocity is } 1 \mathrm{~m} / \mathrm{s} \text { and the } \\
\text { mole fraction of tracer gas is } 0.04\end{array}$} & No air curtain & $\begin{array}{l}\qquad 1.4(2.5 \mathrm{ACH}) \\
\text { (two air outlets on the side of consulting desk are } \\
\text { transferred into one air inlet and one air outlet) }\end{array}$ \\
\hline \multirow{3}{*}{1} & Case 1 & & $0^{\circ}$ & 2 \\
\hline & Case 2 & & $0^{\circ}$ & 3 \\
\hline & Case 3 & & $0^{\circ}$ & 4 \\
\hline \multirow{3}{*}{2} & Case 4 & & $20^{\circ}$ & 2 \\
\hline & Case 5 & & $20^{\circ}$ & 3 \\
\hline & Case 6 & & $20^{\circ}$ & 4 \\
\hline \multirow{3}{*}{3} & Case 7 & & $40^{\circ}$ & 2 \\
\hline & Case 8 & & $40^{\circ}$ & 3 \\
\hline & Case 9 & & $40^{\circ}$ & 4 \\
\hline \multirow{3}{*}{4} & Case 1 & & $0^{\circ}$ & 2 \\
\hline & Case 4 & & $20^{\circ}$ & 2 \\
\hline & Case 7 & & $40^{\circ}$ & 2 \\
\hline \multirow{3}{*}{5} & Case 2 & & $0^{\circ}$ & 3 \\
\hline & Case 5 & & $20^{\circ}$ & 3 \\
\hline & Case 8 & & $40^{\circ}$ & 3 \\
\hline \multirow{3}{*}{6} & Case 3 & & $0^{\circ}$ & 4 \\
\hline & Case 6 & & $20^{\circ}$ & 4 \\
\hline & Case 9 & & $40^{\circ}$ & 4 \\
\hline
\end{tabular}

Note: Supply air angle $\theta\left({ }^{\circ}\right)$ suggests angle between supply air flow and vertical direction of consulting desk (pointed to the patient), shown in Figure 1 . 
sure the same airflow volume in the consulting ward. The equivalent ventilation rate was set to $2.5 \mathrm{ACH}$, which equals to Case 1.

\subsection{Grid independence test}

Taking Case 1 as an example, three different meshes were generated to identify the least required amount of meshes. Mesh details were shown in Figure 2, where grids around the human body were particularly refined with size varied from $0.001 \mathrm{~m}$ to $0.1 \mathrm{~m}$ to fit dramatic gradients of velocity field and temperature field surrounding human body. Figure 3 displayed that the velocity in $Z$-coordinate under Mesh 1 (2,560,503 cells), Mesh 2 (3,072,604 cells) and Mesh 3 $(5,223,426$ cells $)$ almost overlap with each other. Some small differences were probably accounted for the occasionality of CFD calculation (Liu et al. 2017b). Thus, the grid independence of meshes has been verified and the smallest required grids in Mesh 1 is used for the following simulations.

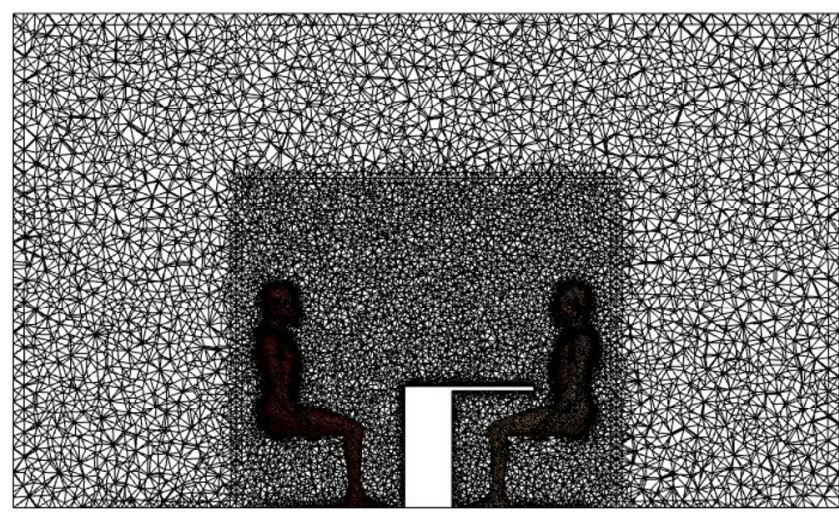

Fig. 2 Mesh detail corresponding to 2.56 million grid elements

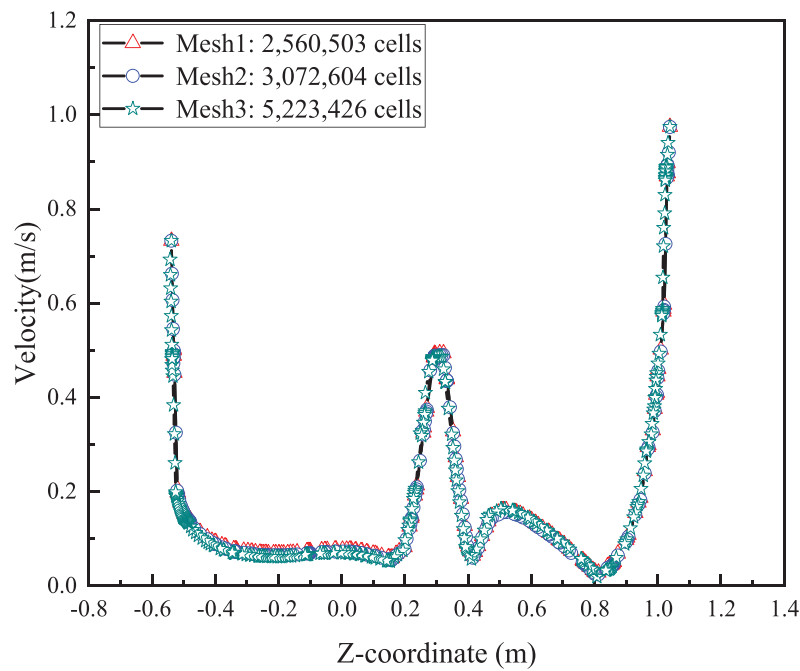

Fig. 3 Velocity distribution comparison between three meshes of Case 1

\section{Results and discussion}

The cutting-off performance of air curtains can be evaluated by the airflow patterns, the dispersion of exhaled pollutants, the horizontal variation of exhaled pollutants, the concentrations on average and at the doctor's mouth, the dynamic process of exhaled droplets.

\subsection{Airflow patterns in the consulting ward}

Figure 4 showed velocity vectors under various supply air parameters. When the supply air velocity is $2 \mathrm{~m} / \mathrm{s}$, the velocity of airflow around the doctor's area was smaller with the increasing supply air angle from $0^{\circ}$ to $40^{\circ}$ shown in Figures 4(b), (e) and (h). Thus, less patient exhaled flow moved into the doctor's breathing zone. For the supply air velocity $3 \mathrm{~m} / \mathrm{s}$, strong turbulence was observed behind the patient at supply air angle $20^{\circ}$ shown in Figure $4(\mathrm{f})$, which enhanced mixing airflow in the consulting ward and increases the doctor's exposure to the patient exhaled pollutants. The air curtains formed by the supply air angle $40^{\circ}$ was close to the patient's mouth and the airflow around the patient came into a vortex-like flow shown in Figure 4(i). Thus, most of the patient exhaled pollutants were controlled in a circular range and the mass fraction of tracer gas near the doctor's mouth was lower than that at supply air angle $20^{\circ}$. Then as the supply air velocity increased to $4 \mathrm{~m} / \mathrm{s}$, turbulence was much stronger along with air curtains upward the ceilings and then backward the patient at supply air angle $40^{\circ}$ shown in Figure $4(\mathrm{~g})$. The entrainment of air curtains also got stronger, which helped strengthen the isolation performance of air curtains and protect the doctor's area.

\subsection{Dispersion of patient exhaled pollutants}

Figure 5(a) showed the distributions of mass fraction of $\mathrm{CO}_{2}$ in the consulting ward under normal consulting desk without air curtains, while Figures $5(b)$ to $(j)$ displayed the distributions of mass fraction of $\mathrm{CO}_{2}$ in a consulting ward under consulting desks with different supply air velocity and supply air angle.

To maintain stable airflow pattern in the consulting ward, the two supply air inlets on the table were removed and the two outlets on both sides are changed into one inlet and one outlet respectively on each side of the normal consulting desk. The exhaled pollutants flowed upside due to buoyance of hot exhaled air and plume generated by thermal manikin. Then the patient exhaled pollutants dispersed towards the doctor at lower height compared height compared to that with air curtains. Compared with the consulting desk with supply air velocity $2 \mathrm{~m} / \mathrm{s}$ and supply air angle $0^{\circ}$, 




(a)

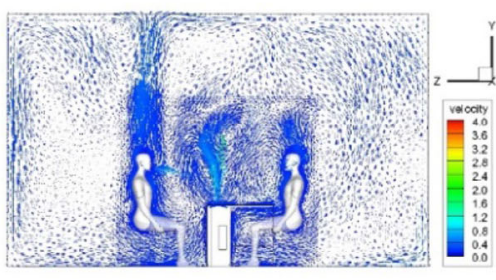

(b)

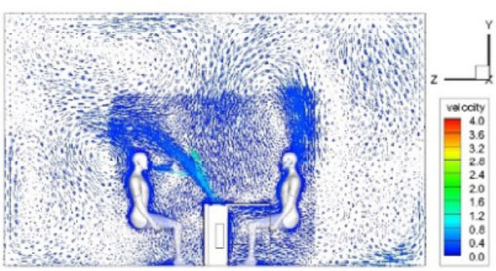

(e)

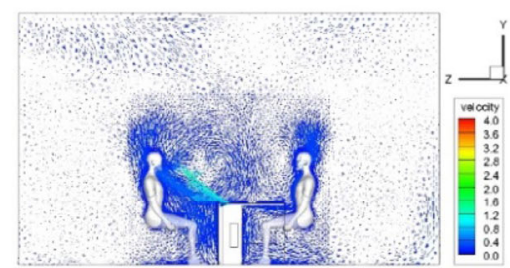

(h)

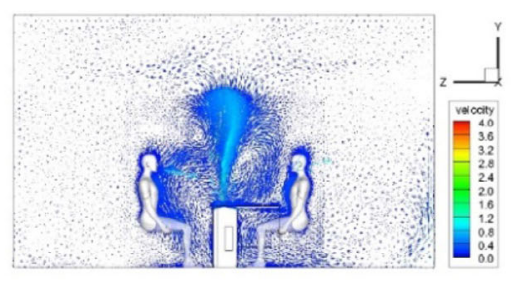

(c)

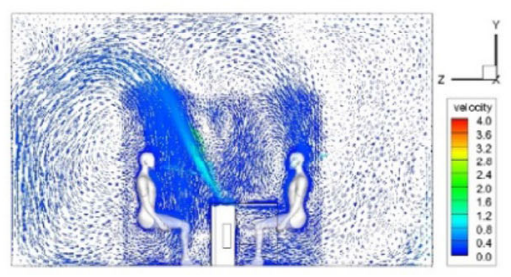

(f)

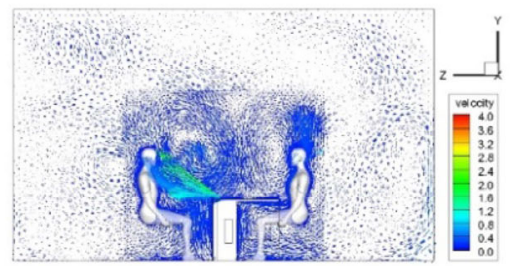

(i)

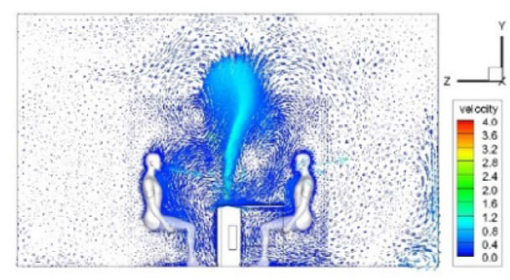

(d)

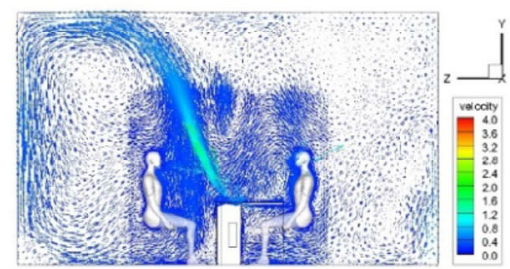

(g)

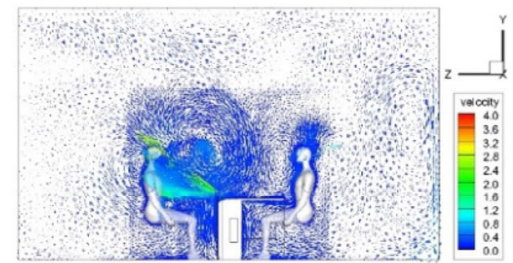

(j)

Fig. 4 Distributions of velocity vectors under various supply air parameters: (a) without air curtains; (b) angle $0^{\circ}$, velocity $2 \mathrm{~m} / \mathrm{s}$; (c) angle $0^{\circ}$, velocity $3 \mathrm{~m} / \mathrm{s}$; (d) angle $0^{\circ}$, velocity $4 \mathrm{~m} / \mathrm{s}$; (e) angle $20^{\circ}$, velocity $2 \mathrm{~m} / \mathrm{s}$; (f) angle $20^{\circ}$, velocity $3 \mathrm{~m} / \mathrm{s}$; (g) angle $20^{\circ}$, velocity $4 \mathrm{~m} / \mathrm{s}$; (h) angle $40^{\circ}$, velocity $2 \mathrm{~m} / \mathrm{s}$; (i) angle $40^{\circ}$, velocity $3 \mathrm{~m} / \mathrm{s}$; (j) angle $40^{\circ}$, velocity $4 \mathrm{~m} / \mathrm{s}$

stable air curtain was observed in front of the doctor shown in Figure 5(b), preventing the patient exhaled flow from directly flowing to the doctor breath zone. Though the patient exhaled flow first moved vertically towards the ceiling but then moved horizontally towards the doctor's area in a certain height, the pollutant concentration in the head and breath zone of the doctor were kept at a lower level compared to the consulting desk without air curtain in Figure 5(a).

To explore the effect of supply air velocity on the dispersion of patient exhaled flow, Figure 5 displayed the species distribution of tracer gas in the ward under different supply air velocity varying from $2 \mathrm{~m} / \mathrm{s}, 3 \mathrm{~m} / \mathrm{s}, 4 \mathrm{~m} / \mathrm{s}$ with different supply air angle, i.e. $0^{\circ}, 20^{\circ}, 40^{\circ}$. Nine cases were divided into three scenarios, i.e. Case 1 to Case 3 (shown as Figures 5(b) to (d)) at supply air angle $0^{\circ}$, Case 4 to Case 6 (shown as Figures 5(e) to (g)) at supply air angle $20^{\circ}$, Case 7 to Case 9 (shown as Figures 5(h) to (j)) at supply air angle $40^{\circ}$. Compared to Figures 5(c) and (d), the height of air curtains was limited and lower in Figure 5(b). The patient exhaled pollutants flowed upward the patient's head and began to flow horizontally from a lower height that was only a little higher than the doctor's head. Figure 5(c) showed the supply air forms relatively complete air curtains at the supply air velocity $3 \mathrm{~m} / \mathrm{s}$ and the patient exhaled flow was blocked on the left zone of air curtain. Figure 5(d) showed that the supply air with $4 \mathrm{~m} / \mathrm{s}$ also forms strong air curtains to isolate 


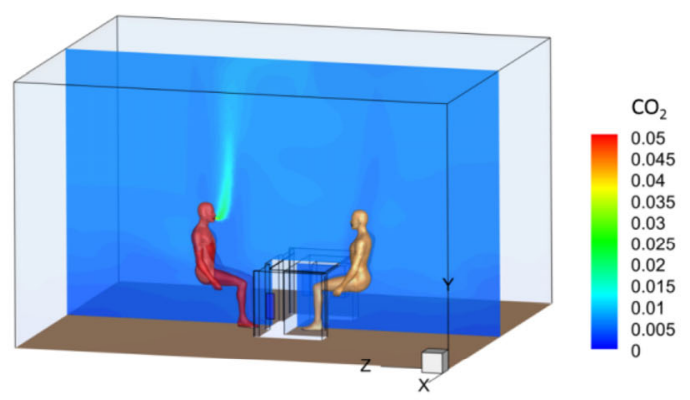

(a)

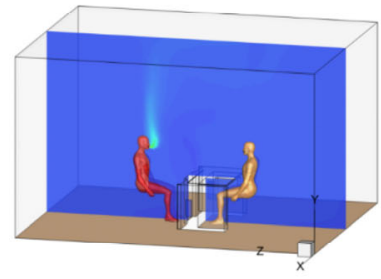

(b)

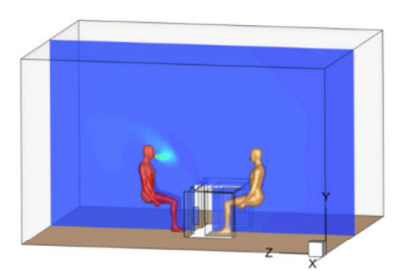

(e)

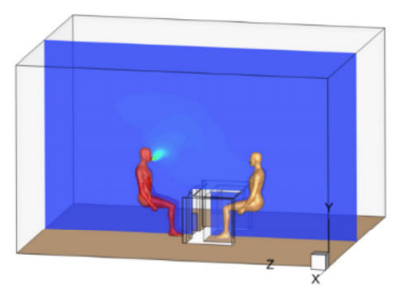

(h)

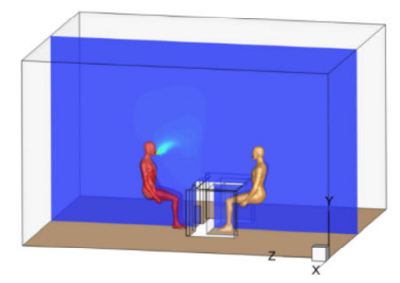

(c)

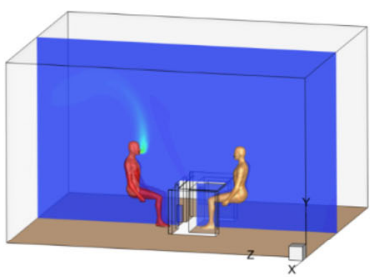

(f)

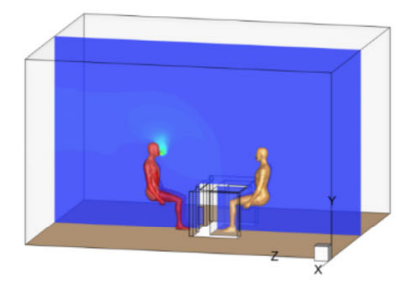

(i)

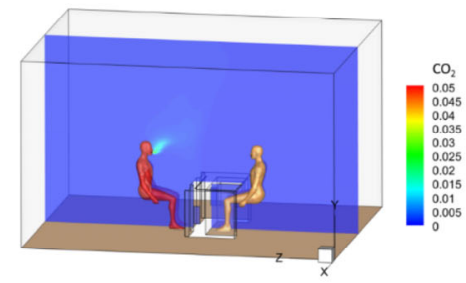

(d)

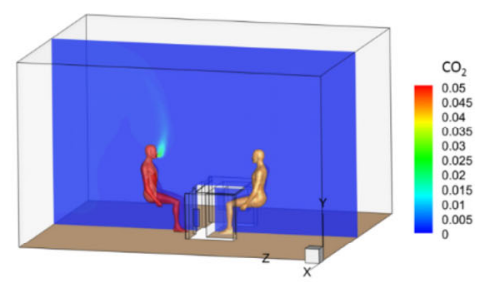

(g)

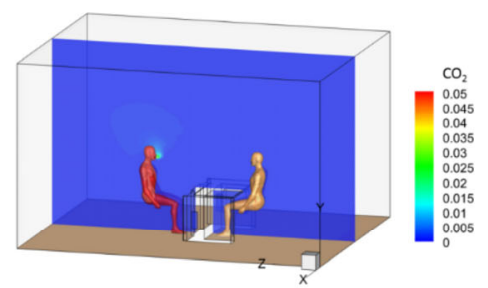

(j)

Fig. 5 Distributions of mass fraction of $\mathrm{CO}_{2}$ under various supply air parameters: (a) without air curtains; (b) angle $0^{\circ}$, velocity $2 \mathrm{~m} / \mathrm{s}$; (c) angle $0^{\circ}$, velocity $3 \mathrm{~m} / \mathrm{s}$; (d) angle $0^{\circ}$, velocity $4 \mathrm{~m} / \mathrm{s}$; (e) angle $20^{\circ}$, velocity $2 \mathrm{~m} / \mathrm{s}$; (f) angle $20^{\circ}$, velocity $3 \mathrm{~m} / \mathrm{s}$; (g) angle $20^{\circ}$, velocity $4 \mathrm{~m} / \mathrm{s}$; (h) angle $40^{\circ}$, velocity $2 \mathrm{~m} / \mathrm{s}$; (i) angle $40^{\circ}$, velocity $3 \mathrm{~m} / \mathrm{s}$; (j) angle $40^{\circ}$, velocity $4 \mathrm{~m} / \mathrm{s}$

the patient and the doctor on a small tilt to the doctor.

Figures 5(e) to $(\mathrm{g})$ presented the patient exhaled flow at supply air angle $20^{\circ}$. Due to the tilted angle of supply air, the patient exhaled pollutants was suppressed by air curtains and moves upwards and rearwards the patient. The air curtains were partly formed and the exhaled pollutants were still able to move over the air curtains under supply air velocity $2 \mathrm{~m} / \mathrm{s}$ and $3 \mathrm{~m} / \mathrm{s}$, shown in Figures 5(e) and (f). With supply air velocity increased to $4 \mathrm{~m} / \mathrm{s}$, complete air curtains were formed, enabling the patient exhaled flow mainly concentrated on the patient zone, shown in Figure 5(g). It was found that the patient exhaled flow moved much higher along with the stronger air curtains, which could be accounted by the supply air entrainment.
Figures $5(\mathrm{~h})$ to $(\mathrm{j})$ demonstrated the patient exhaled flow under different supply air velocity at supply air angle $40^{\circ}$. The tracer gas dispersed directly towards the doctor shown in Figure 5(h), indicating that patient exhaled flow was not suppressed by air curtains but easy to penetrate to the breathing zone of the doctor. It may be attributed to the jet (air curtains) that was attached to the surface of the consulting desk, failing to separate the patient and the doctor. With the supply air velocity increased, the jet flowing to the patient became stronger, pushing the patient exhaled flow and plume backward, making the tracer gas concentration around the doctor's zone lower. However, it would cause a sensation of draught to the patient, clearly shown in Figures 5(h)-(j). 
To explore the effect of supply air angle on dispersion of patient exhaled flow, nine cases were divided into three scenarios, i.e. Cases 1, 4, 7 (shown as Figures 5(b), (e), (h)) with supply air velocity $2 \mathrm{~m} / \mathrm{s}$, Cases 2, 5, 8 (shown as Figures 5(c), (f), (i)) with supply air velocity $3 \mathrm{~m} / \mathrm{s}$ and Cases 3, 6, 9 (shown as Figures 5(d), (g), (j)) with supply air velocity $4 \mathrm{~m} / \mathrm{s}$.

Figures 5(b), (e) and (h) displayed the patient exhaled flow under different supply air angle with supply air velocity $2 \mathrm{~m} / \mathrm{s}$. Compared to Figure 5(a) at supply air angle $0^{\circ}$, the air curtain generated by supply air angle $20^{\circ}$ can effectively control the exhaled flow of the patient blocked in a small zone behind the patient shown in Figure 5(e). As the supply air angle increased to $40^{\circ}$ shown in Figure 5(h), the patient exhaled pollutants flowed towards the doctor over air curtains and the doctor was directly exposed to the pollutants, increasing the infection risk in real consulting ward.

Figures 5(c), (f) and (i) presented the patient's exhaled flow under different supply air angle with supply air velocity $3 \mathrm{~m} / \mathrm{s}$. The patient exhaled pollutants flowed forward to the doctor's area at supply air angle $0^{\circ}$ shown in Figure 5(c), but it flowed backward the patient at supply air angle $20^{\circ}$ shown in Figure 5(f). Similarly, the patient exhaled pollutants was partly suppressed at the supply air angle $20^{\circ}$. Figure 5(i) showed that the patient exhaled pollutants flowed around the patient and some moves towards the doctor area while others move backward the patient at supply air angle $40^{\circ}$.

Figures 5(d), (g) and (j) showed the patient exhaled flow under different supply air angles with supply air velocity $4 \mathrm{~m} / \mathrm{s}$. Obvious concentration boundary of tracer gas was observed at supply air angle $0^{\circ}$ shown in Figure 5(d) and the patient exhaled pollutants flowed a little forward the doctor's area. When the supply air angle increased to $20^{\circ}$ shown in Figure $5(\mathrm{~g})$, the patient exhaled pollutants moved straight to the ceiling wall and then down to the back area of the patient. When the supply air angle increased to $40^{\circ}$, the specific area of tracer gas concentration around the patient showed that the patient exhaled flow distributes in a small area around the patient's head.

Species profiles of tracer gas $\mathrm{CO}_{2}$ suggested that both supply air velocity and supply air angle played an important role in the dispersion of patient exhaled pollutant. Air curtains were observed significantly at the supply air angle $20^{\circ}$. When the supply air velocity was low, i.e. $2 \mathrm{~m} / \mathrm{s}$ and $3 \mathrm{~m} / \mathrm{s}$, air curtains were partly formed and patient exhaled flow can move towards the doctor. For larger supply air velocity, i.e. $4 \mathrm{~m} / \mathrm{s}$, air curtains were completely formed from the supply air outlets on the consulting desk until the ceiling wall. What's more, the simulation results about cut-off performance of air curtains in this present study conformed to previous results in literature. Yang-Cheng et al. found that the air curtain device realized the optimal sealing performance at the moderate ejection velocity of $5 \mathrm{~m} / \mathrm{s}$ with the variation from $3 \mathrm{~m} / \mathrm{s}$ to $7 \mathrm{~m} / \mathrm{s}$ (Shih et al. 2011). Besides, the larger ejection angle of $30^{\circ}$ (ranging from $0^{\circ}$ to $30^{\circ}$ ) didn't showed maximum sealing efficiency, which is consistent with results in this study that small angle $\left(20^{\circ}\right)$ is preferable where velocity is larger than $3 \mathrm{~m} / \mathrm{s}$.

\subsection{The horizontal variation of patient exhaled pollutants}

The variation of mass fraction of tracer gas $\mathrm{CO}_{2}$ with the initial mass fraction 0.04 indicated the dispersion of patient exhaled pollutants. Figure 6 shows the concentration of tracer gas varies along with the horizontal distance from the patient mouth. The mass fraction of tracer gas declined rapidly in the first $0.1 \mathrm{~m}$ from the patient's mouth and then varies at a lower concentration, except Case 4 (supply air angle $20^{\circ}$, supply air velocity $2 \mathrm{~m} / \mathrm{s}$ ). The mass fraction of tracer gas in Case 4 decreased similarly with other cases for the first $0.1 \mathrm{~m}$ but then begins to decrease slowly, and it comes the lower concentration until $0.42 \mathrm{~m}$ from the patient's mouth.

For Case 0 without air curtains, the lowest mass fraction of tracer gas, i.e. 0.005 appeared at $0.2 \mathrm{~m}$ from the patient, followed by a slight increase between $0.2 \mathrm{~m}$ and $0.42 \mathrm{~m}$. Then it remained approximately 0.00625 between $0.42 \mathrm{~m}$ and $1.42 \mathrm{~m}$, but decreased near the doctor's mouth between $1.42 \mathrm{~m}$ and $1.5 \mathrm{~m}$. On the contrary, the stable mass fraction for consulting desk with air curtains ranged from 0.00098 to 0.0025 at different horizontal distance between $0.42 \mathrm{~m}$ and $1.5 \mathrm{~m}$, which was much lower than that without air curtains.

The lowest mass fraction of tracer gas depended on different supply air angle and supply air velocity. Figure 7 displayed the detailed variation of the mass fraction of tracer gas and the minimum value, shown in red circle. It was found

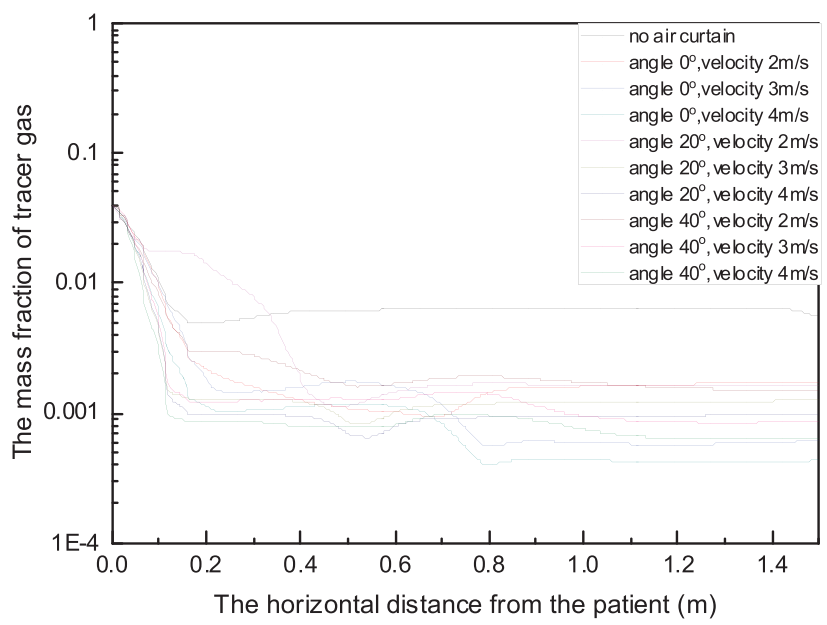

Fig. 6 The mass fraction of tracer gas along with horizontal distance from the patient mouth 

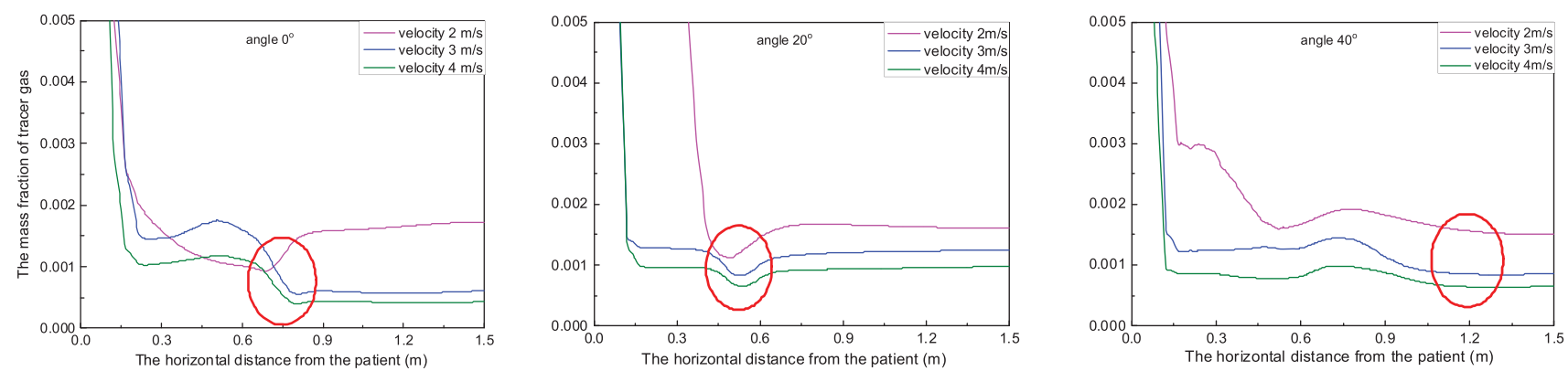

Fig. 7 Effects of supply air angle and velocity on the mass fraction of tracer gas

that the mass fraction of tracer gas at supply air velocity $3 \mathrm{~m} / \mathrm{s}$ and $4 \mathrm{~m} / \mathrm{s}$ varied similarly. A significant decrease of the mass fraction of tracer gas appears at $0.7 \mathrm{~m}$ at supply air angle $0^{\circ}$, which forms vertical air curtains more easily. However, at supply air angle $20^{\circ}$, the mass fraction of tracer gas fell greatly at $0.42 \mathrm{~m}$, which was closer to the patient due to the inclination towards the patient. Compared to supply air angle $0^{\circ}$ and $20^{\circ}$, the mass fraction of tracer gas under supply air angle $40^{\circ}$ increased at about $0.6 \mathrm{~m}$ and then decreased at about $0.72 \mathrm{~m}$. Then the lowest concentration appeared around at $1.2 \mathrm{~m}$. This indicates that the air curtains made a difference on the dispersion distance and the lowest concentration of patient exhaled pollutants appeared within air curtains flow, which was linked to the supply air angle.

\subsection{Concentrations on average and at doctor's mouth}

To assess overall performance of air curtains, the mean concentrations of the consulting ward were analyzed based on the simulation results. Figure 8 showed the mean concentrations of patient exhaled pollutants in the consulting ward and the reduced percentage to normal consulting desk without air curtains. Significant decrease (70\%-90\%) of the mean concentration of exhaled pollutants was observed in the consulting ward with air curtains compared to the normal consulting desk without air curtains. In the consulting ward of normal consulting desk without air curtains, the mean concentration is 0.00568 at the stable condition. Notably, the mean mass fraction of $\mathrm{CO}_{2}$ decreased to 0.000562-0.00169 varying from different supply air velocity and angle. The lowest average mass fraction of $\mathrm{CO}_{2}$ occurred at supply air angle $0^{\circ}$ and supply air velocity $4 \mathrm{~m} / \mathrm{s}$. Greater supply air velocity showed better performance in terms of average mass fraction of $\mathrm{CO}_{2}$. With supply air velocity increasing from $2 \mathrm{~m} / \mathrm{s}$ to $4 \mathrm{~m} / \mathrm{s}$, the average mass fraction of $\mathrm{CO}_{2}$ fell down for supply air angle $0^{\circ}$ (from 0.00169 to 0.000562 ), $20^{\circ}$ (from 0.00163 to 0.000935 ), $40^{\circ}$ (from 0.00138 to 0.000666 ). On the contrary, the optimal supply air angle is linked to supply air velocity. For the supply air velocity at $2 \mathrm{~m} / \mathrm{s}$, increasing supply air angle reduced the average mass fraction of $\mathrm{CO}_{2}$.
For the higher supply air velocity, i.e. $3 \mathrm{~m} / \mathrm{s}$ and $4 \mathrm{~m} / \mathrm{s}$, the average mass fraction of $\mathrm{CO}_{2}$ first went up and then dropped down.

To evaluate the doctor's direct exposure to the patient exhaled pollutants, the mass fraction of $\mathrm{CO}_{2}$ at the doctor's mouth were investigated under various supply air parameters, shown in Figure 9. The mass fraction of $\mathrm{CO}_{2}$ at the doctor's

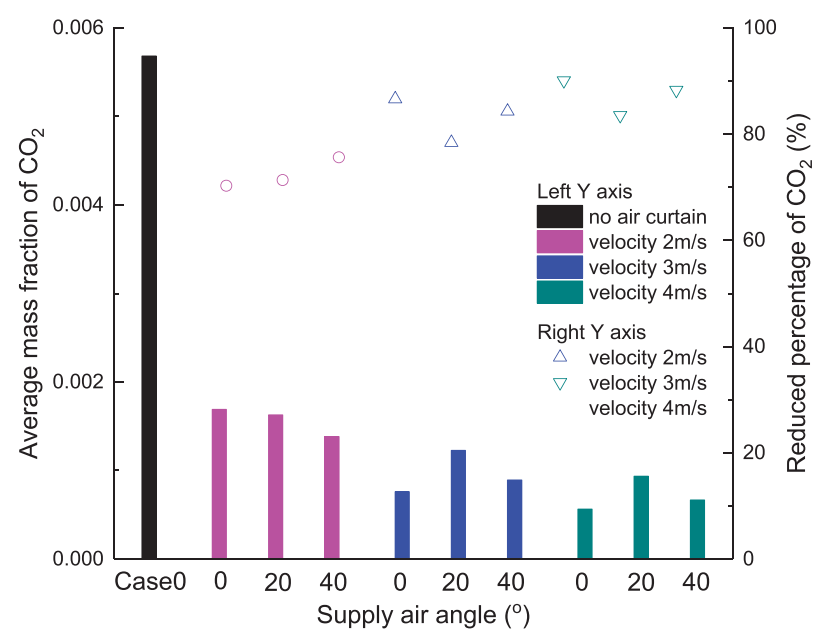

Fig. 8 The mean concentration of $\mathrm{CO}_{2}$ in the consulting ward and reduced percentage to normal consulting desk

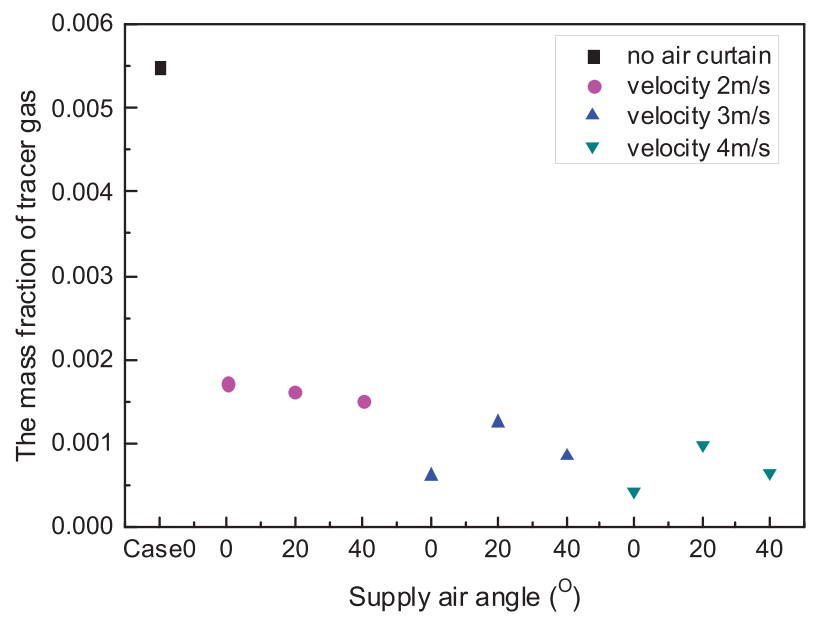

Fig. 9 The mass fraction of $\mathrm{CO}_{2}$ at the doctor's mouth 
mouth of consulting desk with air curtains were significantly lower than that without air curtains, suggesting the great importance of employing air curtains on the consulting desk. It was found that increasing supply air angle was beneficial to reduce the mass fraction of $\mathrm{CO}_{2}$ at the doctor's mouth at lower supply air velocity. The mass fraction of tracer gas decreased $14.7 \%$, i.e. from 0.00172 to 0.0015 , for supply air velocity $2 \mathrm{~m} / \mathrm{s}$ shown in red dots in Figure 9. However, increasing supply air angle was not always good for controlling the patient exhaled pollutants near the doctor's mouth for larger supply air velocity. The mass fraction of tracer gas first increased and then decreased with the increasing supply air angle for supply air velocity $3 \mathrm{~m} / \mathrm{s}$ and $4 \mathrm{~m} / \mathrm{s}$ respectively shown in blue dots and green dots in Figure 9.

\subsection{Time-resolved dispersion characteristics of exhaled droplets}

In collaborate to the steady distribution of patient exhaled pollutants, the dynamic dispersion characteristics of patient exhaled droplet were investigated under different supply air angle. The DPM model (Discrete Phase Model) was employed to calculate the two-phase flow, i.e. droplets and air. In this study, Scenario 5 (Cases 2, 5, 8) with supply air velocity $3 \mathrm{~m} / \mathrm{s}$ was selected as an illustration and the dispersion of patient exhaled droplets at $5 \mathrm{~s}$ was displayed below in Figure 10. Both of evaporation process and dispersion process were considered in this simulation. Detailed animation of droplet trajectories can be found in the Electronic Supplementary Material (ESM) in the online version of this paper.

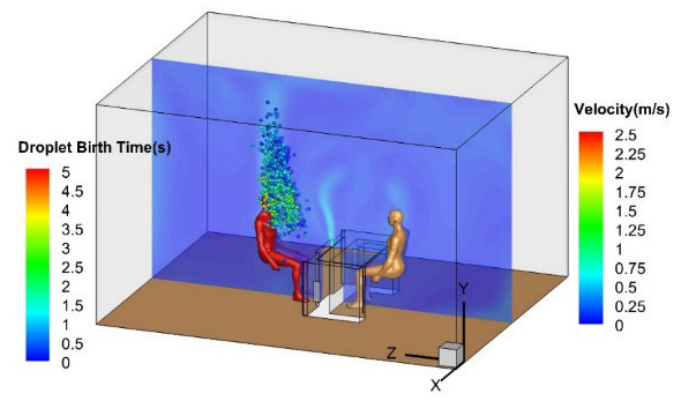

(a)
Figure 10(a) presented the droplet trajectory from the droplet birth at $0 \mathrm{~s}$ to $5 \mathrm{~s}$ under the supply air angle $0^{\circ}$. Air curtains were formed vertically from the supply air outlets and mix with ambient air in the ward. The droplets were exhaled from the patient and then evaporated into dry droplet nuclei. Most of the droplets concentrated on the left of the air curtains, i.e. the patient's side. Some droplets moved upwards to the ceiling wall once being exhaled from the patient and a small amount of droplets fell downwards to the ground. The initial droplets have almost arrived near the ceiling at time $5 \mathrm{~s}$.

Figure 10(b) demonstrated the droplet trajectory from the droplet birth at $0 \mathrm{~s}$ to $5 \mathrm{~s}$ under the supply air angle $20^{\circ}$. Similar with Figure 5(f), most droplets focused on the left of the air curtains. The droplets were effectively suppressed by the air curtains and moved backward of the patient. At $5 \mathrm{~s}$, the initial droplets appeared at the medium height of the ward, with was a little higher over the patient's head and then tend to drop down to the ground.

Figure 10(c) displayed the droplet trajectory from the droplet birth at $0 \mathrm{~s}$ to $5 \mathrm{~s}$ under the supply air angle $40^{\circ}$. Unlike the supply air angle at $0^{\circ}$ and $20^{\circ}$, the droplets dispersed completely different at supply air angle $40^{\circ}$. Most droplets appeared on the right of the air curtains and moved upwards and forward to the doctor's area. This could be accounted for the lower position of air curtains caused by the greater supply air angle. The droplets moved more uniformly at different time step and the initial droplets appeared at close height as they appear at supply air angle $20^{\circ}$ but in different direction.

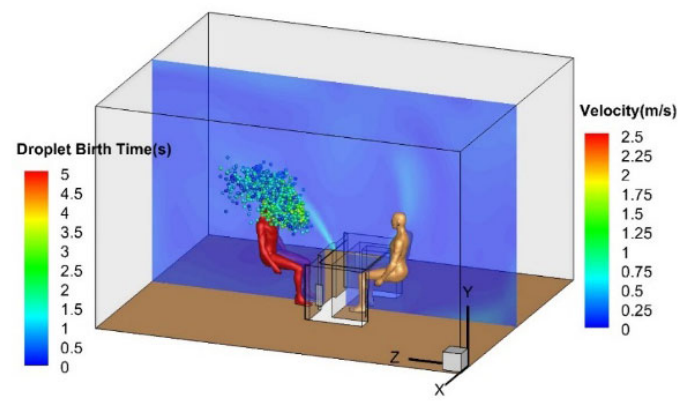

(b)

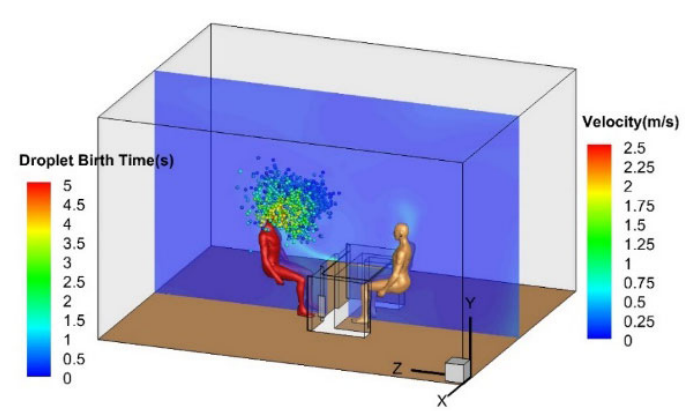

(c)

Fig. 10 Patient exhaled droplets distribution under different supply air angle: (a) angle $0^{\circ}$; (b) angle $20^{\circ}$; (c) angle $40^{\circ}$ 


\section{Conclusion}

The new application of air curtains on the consulting desk is of great potential in reducing the short-range infection risk in consulting wards. The numerical simulation in this paper revealed that the average mass fraction of exhaled pollutants decreases significantly (70\%-90\%) in the consulting ward with air curtains. Both supply air velocity and supply air angle have great effects in its cutting-off performance. Besides, the patient exhaled flow can be suppressed by air curtains under suitable air angle, which is coupled with the supply air velocity. It is found that larger angle $\left(0^{\circ}-40^{\circ}\right)$ is better where velocity is less than $3 \mathrm{~m} / \mathrm{s}$, otherwise a small angle $\left(20^{\circ}\right)$ is preferable where velocity is larger than $3 \mathrm{~m} / \mathrm{s}$. For air curtains with supply air velocity larger than $3 \mathrm{~m} / \mathrm{s}$, exhaled flow could be well suppressed at the supply air angle $20^{\circ}$ but moves over air curtains at $40^{\circ}$. Moreover, higher supply air velocity is better for reducing the patient exhaled pollutants around the doctor's area. However, air curtains with high supply air velocity would easily entrain patient exhaled flow from plume generated by thermal manikin, weakening its cutting-off performance. This study can provide effective and intuitive guidance in practical use of air curtains in consulting wards.

\section{Acknowledgements}

This work is jointed supported by the National Natural Science Foundation of China (No. 51778128), the National Key Research and Development Program of China (No. 2018YFC1200100), the Entrepreneurship Leadership Project in Guangzhou Development Zone of China (No. CY2018-003), and the Scientific Research Foundation of Graduate School of Southeast University (No. YBPY1903).

Electronic Supplementary Material (ESM): supplementary material is available in the online version of this article at https://doi.org/10.1007/s12273-020-0649-7. The ESM files include the animation of patient exhaled droplets from the droplet birth at $0 \mathrm{~s}$ to $5 \mathrm{~s}$ under the supply air angle $0^{\circ}, 20^{\circ}$, $40^{\circ}$, at supply air velocity $3 \mathrm{~m} / \mathrm{s}$.

\section{References}

Amin M, Dabiri D, Navaz HK (2011). Comprehensive study on the effects of fluid dynamics of air curtain and geometry, on infiltration rate of open refrigerated cavities. Applied Thermal Engineering, 31: 3055-3065.

Cao Z, Han H, Gu B (2011). A novel optimization strategy for the design of air curtains for open vertical refrigerated display cases. Applied Thermal Engineering, 31: 3098-3105.

Cao G, Sirén K, Kilpeläinen S (2014). Modelling and experimental study of performance of the protected occupied zone ventilation. Energy and Buildings, 68: 515-531.
Cao G, Nielsen PV, Jensen RL, Heiselberg P, Liu L, Heikkinen J (2015). Protected zone ventilation and reduced personal exposure to airborne cross-infection. Indoor Air, 25: 307-319.

Eames I, Tang JW, Li Y, Wilson P (2009). Airborne transmission of disease in hospitals. Journal of the Royal Society Interface, 6 (supply 6): S697-S702.

Ferkol T, Schraufnagel D (2014). The global burden of respiratory disease. Annals of the American Thoracic Society, 11: 404-406.

Gil-Lopez T, Castejon-Navas J, Galvez-Huerta MA, O’Donohoe PG (2014). Energetic, environmental and economic analysis of climatic separation by means of air curtains in cold storage rooms. Energy and Buildings, 74: 8-16.

Goubran S, Qi D, Wang LL (2017). Assessing dynamic efficiency of air curtain in reducing whole building annual energy usage. Building Simulation, 10: 497-507.

Inouye S, Matsudaira Y, Sugihara Y (2006). Masks for influenza patients: measurement of airflow from the mouth. Japanese Journal of Infectious Diseases, 59: 179-181.

Ji Y, Qian H, Ye J, Zheng X (2018). The impact of ambient humidity on the evaporation and dispersion of exhaled breathing droplets: A numerical investigation. Journal of Aerosol Science, 115: 164-172.

Laguerre O, Hoang MH, Osswald V, Flick D (2012). Experimental study of heat transfer and air flow in a refrigerated display cabinet. Journal of Food Engineering, 113: 310-321.

Li Y, Huang X, Yu ITS, Wong TW, Qian H (2005). Role of air distribution in SARS transmission during the largest nosocomial outbreak in Hong Kong. Indoor Air, 15: 83-95.

Lidwell OM, Williams REO (1961). The epidemiology of the common cold. I. Journal of Hygiene, 59: 309-319.

Liu L, Wei J, Li Y, Ooi A (2017a). Evaporation and dispersion of respiratory droplets from coughing. Indoor Air, 27: 179-190.

Liu L, Li Y, Nielsen PV, Wei J, Jensen RL (2017b). Short-range airborne transmission of expiratory droplets between two people. Indoor Air, 27: 452-462.

Liu F, Zhang C, Qian H, Zheng X, Nielsen PV (2019). Direct or indirect exposure of exhaled contaminants in stratified environments using an integral model of an expiratory jet. Indoor Air, 29: 591-603.

MacIntyre CR, Wang Q, Seale H, Yang P, Shi W, et al. (2013). A randomized clinical trial of three options for $\mathrm{N} 95$ respirators and medical masks in health workers. American Journal of Respiratory and Critical Care Medicine, 187: 960-966.

MacIntyre CR, Seale H, Dung TC, Hien NT, Nga PT, Chughtai AA, Rahman B, Dwyer DE, Wang Q (2015). A cluster randomised trial of cloth masks compared with medical masks in healthcare workers. BMJ Open, 5: e006577.

MacIntyre CR, Zhang Y, Chughtai AA, Seale H, Zhang D, Chu Y, Zhang H, Rahman B, Wang Q (2016). Cluster randomised controlled trial to examine medical mask use as source control for people with respiratory illness. BMJ Open, 6: e012330.

Nielsen PV, Buus M, Winther F, Thilageswaran M (2008). Contaminant flow in the microenvironment between people under different ventilation conditions. ASHRAE Transactions, 114(2): 632-638.

Novel Coronavirus Pneumonia Emergency Response Epidemiology Team (2020). Epidemiological and clinical features of the 2019 novel coronavirus outbreak in China. Chinese Journal of Epidemiology, 41: 145-151. (in Chinese) 
Saarinen P, Kalliomäki P, Koskela H, Tang JW (2018). Large-eddy simulation of the containment failure in isolation rooms with a sliding door-An experimental and modelling study. Building Simulation, 11: 585-596.

Shih YC, Yang AS, Lu C (2011). Using air curtain to control pollutant spreading for emergency management in a cleanroom. Building and Environment, 46: 1104-1114.

Tang JW, Liebner TJ, Craven BA, Settles GS (2009). A schlieren optical study of the human cough with and without wearing masks for aerosol infection control. Journal of the Royal Society Interface, 6(suppl_6): S727-S736.

Topp C, Nielsen PV, Sørensen DN (2002). Application of computer simulated persons in indoor environmental modeling/Discussion. ASHRAE Transactions, 108(2): 1084-1090.

Versteeg HK, Malalasekera W (2007). An Introduction to Computational Fluid Dynamics: The Finite Volume Method, 2nd edn. New York: Pearson Education.

Wei J, Li Y (2015). Enhanced spread of expiratory droplets by turbulence in a cough jet. Building and Environment, 93: 86-96.
WHO (2020). Coronavirus disease (COVID-2019) situation reports. World Health Organization. Available at https://www.who.int/ docs/default-source/coronaviruse/situation-reports.

Xie X, Li Y, Chwang ATY, Ho PL, Seto WH (2007). How far droplets can move in indoor environments? Revisiting the Wells evaporation-falling curve. Indoor Air, 17: 211-225.

Zhai ZJ, Zhang Z, Zhang W, Chen QY (2007). Evaluation of various turbulence models in predicting airflow and turbulence in enclosed environments by CFD: Part 1-Summary of prevalent turbulence models. HVAC\&R Research, 13: 853-870.

Zhao F, Shen G, Liu K, Xu Y, Liu D, Wang H (2018). Room airborne pollutant separation by the use of air curtains in the large building enclosure: Infiltration efficiency and partial enclosure ventilation rate. Journal of Building Engineering, 18: 386-394.

Zhou Q, Qian H, Ren H, Li Y, Nielsen PV (2017). The lock-up phenomenon of exhaled flow in a stable thermally-stratified indoor environment. Building and Environment, 116: 246-256. 